\title{
Seroepidemiological study of visceral leishmaniasis in Booyerahmad district, south-west Islamic Republic of Iran
}

\author{
B. Sarkari, ${ }^{1}$ N. Pedram, ${ }^{2}$ M. Mohebali, ${ }^{3}$ A.A. Moshfe, ${ }^{4}$ M.A. Zargar,${ }^{4}$ B. Akhoundi ${ }^{3}$ and M.R. Shirzadi ${ }^{2}$
}

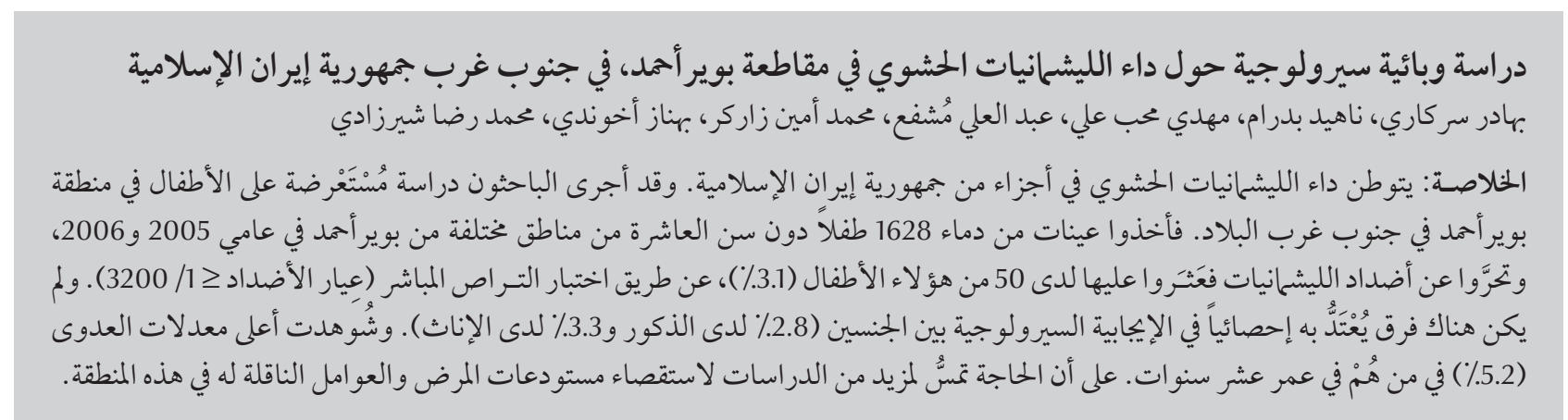

ABSTRACT Visceral leishmaniasis (VL) is endemic in parts of Islamic Republic of Iran. A cross-sectional seroprevalence study was carried out in children in Booyerahmad district in the south-west of the country. Serum samples were taken from 1628 children up to 10 years old from different areas in Booyerahmad in 2005-06. AntiLeishmania antibody was detected in 50 out of 1628 children (3.1\%) by direct agglutination test (antibody titre $\geq 1: 3200$ ). There was no significant difference in seropositivity between the sexes ( $2.8 \%$ males and $3.3 \%$ females). The highest rate of infection (5.2\%) was in the age group 10 years. Further studies are needed to explore the reservoirs and vectors of the disease in this region.

Étude séro-épidémiologique sur la leishmaniose viscérale dans le district de Booyerahmad, sud-ouest de la République islamique $d^{\prime}$ Iran

RÉSUMÉ La leishmaniose viscérale est endémique dans certaines régions de la République islamique d'Iran. Une étude transversale sur la séroprévalence a été menée auprès d'enfants du district de Booyerahmad dans le sudouest du pays. Des échantillons de sérum ont été prélevés sur 1628 enfants âgés de 0 à 10 ans dans différentes zones de Booyerahmad en 2005-2006. L'anticorps anti-leishmania a été détecté chez 50 des 1628 enfants (3,1 \%) par un test d'agglutination directe (titre des anticorps $\geq 1: 3200$ ). Aucune différence significative entre les sexes n'a été constatée en ce qui concerne la séropositivité (2,8\% chez les garçons et 3,3\% chez les filles). Le taux d'infection le plus élevé (5,2\%) se trouvait dans le groupe des enfants de 10 ans. Des études complémentaires sont nécessaires pour étudier les réservoirs et les vecteurs de la maladie dans cette région.

${ }^{1}$ Department of Parasitology and Mycology, School of Medicine, Shiraz University of Medical Sciences, Shiraz, Islamic Republic of Iran. ${ }^{2}$ Zoonoses Control Unit, Diseases Management Centre, Ministry of Health, Treatment and Medical Education, Tehran, Islamic Republic of Iran. ${ }^{3}$ Department of Medical Parasitology and Mycology, School of Public Health, Tehran University of Medical Sciences, Tehran, Islamic Republic of Iran (Correspondence to M. Mohebali:mohebali@tums.ac.ir).

${ }^{4}$ Department of Parasitology, Faculty of Medicine, Yasuj University of Medical Sciences, Yasuj, Islamic Republic of Iran.

Received: 19/02/09; accepted: 27/05/09 


\section{Introduction}

The leishmaniases are endemic diseases in 88 countries in the world [1]. Visceral leishmaniasis (VL) is caused by the Leishmania donovani complex, including $L$. donovani in the Indian subcontinent and East Africa, L. infantum in Mediterranean areas and the Middle East and L. chagasi in Latin America [2]. VL is endemic in 62 countries, 500000 new cases occur annually and 200 million people are at risk worldwide [1].

Visceral or cutaneous forms ofleishmaniasis are present in at least 20 out of the 31 provinces of the Islamic Republic of Iran and VL is endemic in the south (Fars province) and north-west (East Azarbaijan and Ardabil province) of the country [3-6]. The Mediterranean type of VL, caused by L. infantum, is also present in the Islamic Republic of Iran. Estimates of the seroprevalence of VL in various areas of the country range from $0.5 \%$ to $5 \%[7]$.

Cases of VL have been reported from different parts of Kohgiloyeh and Booyerahmad province in the southwest of the Islamic Republic of Iran. A review of hospital records in Yasuj, the capital of the province, revealed that during 1998-2001, 57 cases of VL were admitted to Yasuj hospitals. This means that $\mathrm{VL}$ is an endemic disease in this region, but the scale of the disease and seroprevalence rate are unknown. The current study was therefore conducted to determine the seroprevalence of $\mathrm{VL}$ in children in Booyerahmad district (the largest and most populated township of the province).

\section{Methods}

\section{Study area and community}

This epidemiological study was conducted in Booyerahmad district, south-west Islamic Republic of Iran $\left(30^{\circ} 40^{\prime} \mathrm{N}, 51^{\circ} 35^{\prime} \mathrm{E}\right)$ in Kohgiluyeh and Booyerahmad province (Figure 1). The district covers an area of approximately
$16264 \mathrm{~km}^{2}$. The region is mountainous and the vegetation of the area includes wild pistachio and tulips and most of the farmland and plains are covered with oak forests. Its population is estimated to be 697 654, among whom $49 \%$ are settled in urban areas and $51 \%$ live in rural areas. The people live mainly on animal farming (sheep, goats and cattle) and gardening.

\section{Serum samples}

Using cluster sampling 6 different areas of Booyerahmad district including the capital of the province, Yasuj, were randomly selected. The sample size was estimated based on the population of the area and a prevalence of VL of about $2 \%$ in other VL-endemic areas in the Islamic Republic of Iran. Altogether 1628 serum samples were taken from children up to 10 years old over an 11-month period of from September 2005 to July 2006. Active case finding was carried out in 6 clusters (villages) selected randomly from about 300 villages of Booyerahmad district. The census in each selected villages was used and serum samples were taken from all children up to 10 years of age. The method for sample collection in Yassuj, which has a large population, was simple by random sampling.

Data on age, sex and place of residence were recorded in a predesigned datasheet. Blood samples were taken from the children using a lancet and microtube and each blood sample was placed on a $3 \mathrm{~mm}$ diameter filter paper. Finger prick blood samples (about 50 $\mu \mathrm{L}$ ) were collected by trained health workers or our expert technicians. The samples were transferred to the leishmaniasis laboratory in the School of Public Health, Tehran University of Medical Sciences for analysis.

Ethical approval of the study was given by the ethics committee of Yasuj University of Medical Sciences and informed consent was obtained from the parents of participants to donate blood samples voluntarily. There were no refusals to participate as before the initiation of this project, the parents of

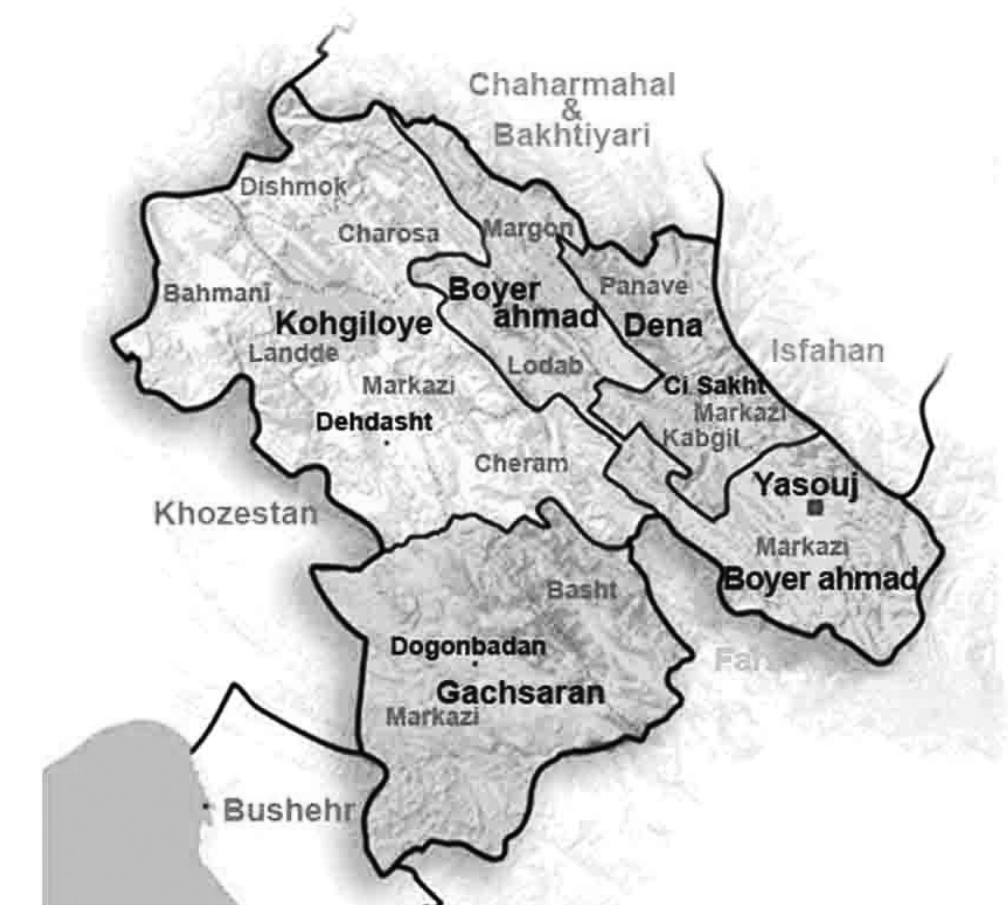

Figure 1 Geographical situation of Booyerahmad district, south-west Islamic Republic of Iran 


\begin{tabular}{|c|c|c|c|c|}
\hline $\begin{array}{l}\text { Table } 1 \text { Ser } \\
10 \text { years ol }\end{array}$ & $\begin{array}{l}\text { ce of visceral leis } \\
\text { erahmad district }\end{array}$ & maniasi & and age & en up to \\
\hline Vairable & No. of samples & $\%$ & DAT pc & $3200)$ \\
\hline & & & No. & $\%$ \\
\hline Sex & & & & \\
\hline Male & 749 & 46.0 & 21 & 2.8 \\
\hline Female & 879 & 54.0 & 29 & 3.3 \\
\hline Age (years & & & & \\
\hline $1-4$ & 219 & 13.5 & 3 & 1.4 \\
\hline 5 & 149 & 9.2 & 1 & 0.7 \\
\hline 6 & 251 & 15.4 & 10 & 4.0 \\
\hline 7 & 344 & 21.0 & 11 & 3.2 \\
\hline 8 & 252 & 15.5 & 11 & 4.4 \\
\hline 9 & 259 & 15.9 & 6 & 2.3 \\
\hline 10 & 154 & 9.5 & 8 & 5.2 \\
\hline Total & 1628 & 100.0 & 50 & 3.1 \\
\hline
\end{tabular}

$D A T=$ direct agglutination test.

children were made aware by health workers of the importance of kala azar in children

\section{Direct agglutination test}

The direct agglutination test (DAT) antigen for this study was prepared in the parasitology department of the School of Health at Tehran University of Medical Sciences. DAT was performed as described by Joshi et al. [8]. The blood spot on each filter paper was punched and serum was eluted from the paper by overnight incubation of each spot in wells with $50 \mu \mathrm{L}$ of distilled water. Then $10 \mu \mathrm{L}$ of the eluted serum was used for screening and testing for anti-Leishmania antibody by DAT in V-shaped microtitre plates. An antibody titre of 1:3200 and above was considered positive $[7,8]$.

\section{Data analysis}

Chi-squared and Fisher exact tests were used to compare seroprevalence values relative to sex, age and district. Analyses were conducted using SPSS software, version 13.5 , with a $P$-value $<0.05$ taken as statistically significant.

\section{Results}

From 1628 collected samples, 749 (46.0\%) were from males and 879 (54.0\%) from females. Anti-Leishmania antibody was detected in the serum of

\begin{tabular}{lccrrrr}
\hline $\begin{array}{l}\text { Table 2 Seroprevalence of Leishmania infection in children in different areas of } \\
\text { Booyerahmad district }\end{array}$ & \multicolumn{7}{c}{ DAT positive } & DAT negative & \multicolumn{2}{c}{ Total } \\
\hline Location & No. & $\%$ & No. & $\%$ & No. & $\%$ \\
Yasuj & 41 & 2.5 & 1041 & 63.9 & 1082 & 66.5 \\
Dashtroom & 0 & 0.0 & 49 & 3.0 & 49 & 3.0 \\
Sarabtaveh & 1 & 0.1 & 99 & 6.1 & 100 & 6.1 \\
Sepidar & 2 & 0.1 & 96 & 5.9 & 98 & 6.0 \\
Madovan & 3 & 0.2 & 163 & 10.0 & 166 & 10.2 \\
Margoon & 3 & 0.2 & 130 & 8.0 & 133 & 8.2 \\
Total & 50 & 3.1 & 1578 & 96.9 & 1628 & 100.0 \\
\hline
\end{tabular}

$D A T=$ direct agglutination test .

50 of the 1628 children (3.1\%) by DAT (antibody titre $\geq 1: 3200$ ). From those 50 cases, $21(2.8 \%)$ were males and 29 (3.3\%) were females, a difference that was not statistically significant $(P=$ 0.43) (Table 1).

Table 1 also shows the seroprevalence of Leishmania spp. infection by age in children up to 10 years age. The highest rate of infection $(5.2 \%)$ was seen in children aged 10 years and the lowest rate $(0.7 \%)$ was found in the age group 5 years. However, the difference in the rate of antibody against Leishmania in children less than $\leq 4$ year old compared with children $4+$ years old was not statistically significant $(P=0.116)$.

Table 2 shows the seroprevalence of Leishmania infection in children in different areas of Booyerahmad district. The highest rate of infection was found in Yasuj (66.5\% of samples tested positve).

\section{Discussion}

VL is a serious public health problem in many tropical and subtropical regions of the world, including the Islamic Republic of Iran. Dogs and other canines are the main reservoirs of VL in our country [9]. Serological surveys have been carried out in different parts of Islamic Republic of Iran to find out the rate of VL infection. In a comprehensive study conducted by Mohebali et al. 12144 serum samples were collected from 4 different geographical zones and tested by DAT [7]. It was found that the seroprevalence of human VL infection ranged from $0.46 \%$ in Khorasan to $5.1 \%$ in Ardabil province.

Cases of VL have been reported from different parts of Kohgiloyeh and Booyerahmad province in the southwest of Islamic Republic of Iran but the prevalence of the disease was previously unknown. Since the Mediterranean type of the disease is present in the Islamic Republic of Iran and the disease in this region is mostly found in infants, 
the subjects of the current study were children. The findings of our study show that anti-Leishmania antibody was detectable in $3.1 \%$ of the studied subjects. Comparing the results of this study with those of Mohebali et al. shows that the prevalence of VL in Booyerahmad district is higher than most other provinces in the Islamic Republic of Iran. The way of life of the inhabitants, such as farming, keeping guard dogs and a nomadic lifestyle, might account for such a high prevalence of VL in this region [10].
The results of our study show no differences in seroprevalence of VL between boys and girls in this area. However, an association between sex and VL infection was observed in Mohebali et al.'s study, where males had a higher rate of VLinfection [7].

In conclusion, the findings of this study demonstrate that VL is an endemic disease, with a relatively high prevalence rate in Kohgiloyeh and Booyerahmad province. Further studies are needed to survey the reservoirs and vectors of the disease in this region.

\section{Acknowledgements}

This investigation received financial support from the office of the ViceChancellor for Research, Yasuj University of Medical Sciences and some of the results were published in Farsi in Armaghan-e-Danesh (a local journal), 2007, 12(2):69-74.

\section{References}

1. Desjeux P. Leishmaniasis: current situation and new perspectives. Comparative Immunology, Microbiology and Infectious Diseases, 2004, 27(5):305-318.

2. Herwaldt BL. Leishmaniasis. Lancet, 1999, 354:1191-1199.

3. Edrissian $\mathrm{GH}$ et al. An endemic focus of visceral leishmaniasis in Meshkin- Shahr, east Azerbaijan province, north-west part of Iran and IFA serological survey of the disease in this area. Bulletin de la Societe de Pathologie Exotique et de ses Filiales, 1988, 81(2):238-248.

4. Mohebali $M$ et al. Seroepidemiological study of visceral leishmaniasis among humans and animal reservoirs in Bushehr province, Islamic Republic of Iran. Eastern Mediterranean Health Journal, 2001, 7(6):912-917.

5. Moshfe A et al. Seroepidemiological study on canine visceral leishmaniasis in Meshkin-shahr district, Ardabil province, northwest of Iran during 2006-2007. Iranian Journal of Parasitology, 2008, 3(3):1-10.

6. Parvizi $\mathrm{P}$ et al. Two Leishmania species circulating in the Kaleybar focus of infantile visceral leishmaniasis, northwest Iran: implications for deltamethrin dog collar intervention. Transactions of the Royal Society of Tropical Medicine and Hygiene, 2008, 102(9):891-897.

7. Mohebali M et al. Application of direct agglutination test (DAT) for the diagnosis and seroepidemiological studies of visceral leishmaniasis in Iran. Iranian Journal of Parasitology, 2006, $1(1): 15-25$.

8. Joshi $\mathrm{AB}$ et al. Evaluation of direct agglutination test (DAT) as an immunodiagnostic tool for diagnosis of visceral leishmaniasis in Nepal. Southeast Asian Journal of Tropical Medicine and Public Health, 1999, 30(3):583-585.

9. Mohebali $\mathrm{M}$ et al. Epidemiological aspects of canine visceral leishmaniosis in the Islamic Republic of Iran. Veterinary Parasitology, 2005, 129(3-4):243-251.

10. Gavgani AS et al. Domestic dog ownership in Iran is a risk factor for human infection with Leishmania infantum. American Journal of Tropical Medicine and Hygiene, 2002, 67(5):511-515. 